\title{
ESTUDO DE CASO SOBRE MANIFESTAÇÕES PATOLÓGICAS CAUSADAS POR UMIDADE EM UMA EDIFICAÇÃO NO INTERIOR DO RIO GRANDE DO SUL
}

\author{
BERNARDI, DANIELI F. \\ Estudante \\ Universidade Federal de Santa Maria \\ Rio Grande do Sul; Brasil \\ danielifaccin@hotmail.com \\ BANDIEIRA, MARIANA \\ Estudante \\ Universidade Federal de Santa Maria \\ Rio Grande do Sul; Brasil \\ marianabandieira@gmail.com
}

\author{
DE GASPERI, JÉSSICA \\ Estudante \\ Universidade Federal de Santa Maria \\ Rio Grande do Sul; Brasil \\ jgasperi1@ucs.br
}

\author{
LIMA, ROGERIO CATTELAN A. DE \\ Servidor Público \\ Universidade Federal de Santa Maria \\ Rio Grande do Sul; Brasil \\ rogerio@ufsm.br
}

\section{RESUMO}

A relevância de uma edificação está atrelada ao seu caráter histórico, cultural ou arquitetônico. Sincronicamente, as construções podem constituir importantes ferramentas de formação e consolidação da identidade local de uma sociedade. No entanto, poucas ou nenhuma manutenção são observadas nestas obras, e a degradação de bens patrimoniais repletos de história levam a perda dos requisitos fundamentais para o seu funcionamento. Neste contexto, o estudo de caso analisado trata de uma edificação emblemática localizada na cidade de Vicente Dutra -RS, extremo norte do estado. O comprometimento do potencial turístico e da vida útil desta estância balneária se associa a vasta ocorrência de manifestações patológicas vinculadas à umidade. Através de uma metodologia de inspeção e análise, o presente trabalho objetiva investigar, mapear e diagnosticar quais as origens e consequências de tais anomalias, vendo como uma demanda social necessária, à disposição de contribuir como base para futuras intervenções.

Palavras-chave: edificação histórica, estância balneária, manifestação patológica, umidade.

\section{ABSTRACT}

The relevance of a building is linked to its character, cultural or architectural history. Synchronously, buildings can be important tools for shaping and consolidating the local identity of a society. However, little or no maintenance is observed in these works, and the degradation of heritage assets full of history leads to the loss of the fundamental requirements for their operation. In this context, the case study analyzed deals with a symbolic edition located in the city of Vicente Dutra-RS, far north of the state. The compromise of the tourist potential and the useful life of this resort is associated with a wide occurrence of pathological manifestations linked to the collection. Through an inspection and analysis methodology, this work aims to investigate, map and diagnose the origins and consequences of such anomalies, seeing as a necessary social demand, with the possibility of contributing as a basis for future analyzes.

Keywords: historical building, seaside resort, pathological manifestation, humidity

\section{INTRODUÇÃO}

As edificações históricas têm um papel fundamental na manutenção da identidade cultural do local onde estão inseridas. Esses bens materiais se consolidam como representações físicas ligadas ao passado, capazes de evidenciar a vida cotidiana dessas comunidades bem como os avanços no desenvolvimento da história da humanidade (MESQUITA; VARUM, 2016).

Se por um lado fica evidente a importância dessas edificações, por outra banda, usualmente aspectos ligados à preservação e recuperação acerca das mesmas são negligenciados. Não obstante, sabe-se ainda que a segurança estrutural de edifícios históricos pode demandar com maior frequência a aplicação de medidas de manutenção quando comparadas a construções modernas (SANTOS, 2016). A falta de conhecimento sobre qual processo construtivo ou quais materiais foram empregados na concepção da construção se confuguram como fatores que entravam a tomada de 
decisões quanto aos métodos de preservação ou mesmo de reabilitação em se tratando de construções desse contexto (MESQUITA; VARUM, 2016).

As manifestações patológicas comprometem a garantia dos principais requisitos de uma edificação, sejam eles: segurança estrutural, estanqueidade à água, conforto térmico, conforto acústico e durabilidade, por isso devem ser evitadas ou corrigidas (CAPORRINO, 2018). Problemas patológicos diretamente atrelados à presença de umidade nas edificações são da ordem de $30 \%$, e se somados os indiretos, esse número pode chegar ao dobro (LOPES, [s.d.]). Isso porque a umidade pode ser a causa ou o meio responsável para a grande maioria das patologias nas construções, como por exemplo, aparecimento de mofo, eflorescências, ferrugem, degradação na pintura e no reboco (VERÇOZA, 1991).

Conforme ainda Verçoza (1991), a umidade nas construções pode ter origem:

- $\quad$ Fase de construção: é natural, necessária e temporária, pois a água presente no concreto, na argamassa e nos demais elementos do processo construtivo, evapora em um prazo de até seis meses;

- Capilaridade: a umidade ascende do solo úmido através de capilares existentes em tijolos, concreto, argamassa e madeira;

- Chuva: considerado o tipo de incidência de umidade mais comum, porém inconstante (dependendo de fatores climático e inerentes à própria edificação);

- Vazamentos em tubulações de água e esgoto: por estarem encobertos pela construção, este tipo de incidência de umidade se torna mais difícil de localizar e corrigir;

- $\quad$ Condensação: neste caso, não se trata da umidade infiltrada, mas sim da umidade presente no ambiente que se deposita nas superfícies devido a diferença térmica entre o ar e a mesma.

A complexidade da análise da incidência de umidade em uma edificação se deve ao fato de que ela pode tanto ser a causa direta do surgimento de uma lesão, como pode ser uma ação indireta, ou seja, se origina como um processo secundário (LOPES, [s.d.]). Assim, este trabalho objetiva analisar as principais manifestações patológicas de umidade, no contexto atual, de uma edificação que compreende o empreendimento balneário local, cuja grande relevância histórica e cultural está atrelada ao surgimento do município de Vicente Dutra.

A discussão a respeito das manifestações patológicas observadas na edificação apresenta as possíveis causas do seu surgimento, visando o desenvolvimento de futuros planos de manutenção no intuito de que através deste estudo, ações de salvaguarda possam ser realizadas por órgãos responsáveis, tencionando que o edifício torne a cumprir seus requisitos funcionais e identitários.

\subsection{Contextualização e caracterização histórica da edificação}

Vicente Dutra está localizado no extremo norte do Rio Grande do Sul, possui 5. 285 habitantes, segundo o censo do IBGE de 2010, e sua economia atual é caracterizada pela agricultura. A questão turística, mesmo sendo constante, ainda é um potencial econômico pouco explorado e com baixos incentivos municipais e estaduais. De acordo com a Secretaria da Cultura, Turismo, Esporte e Lazer do Estado do Rio Grande do Sul, Vicente Dutra faz parte da Rota das Águas e Pedras, englobando cidades do noroeste do estado, como Iraí, Pinheirinho do Vale, Frederico Westphalen e Ametista do Sul.

Conforme dados históricos fornecidos pela Prefeitura Municipal de Vicente Dutra, entre 1935 e 1960 foram construídas duas edificações balneárias modestas e executadas em madeira. Na década de 1970 concluiu-se o terceiro empreendimento balneário com estrutura moldada in loco e vedação de alvenaria, com linhas modernistas que conferiam inovação ao município em uma época que as construções locais ainda eram primariamente em alvenaria estrutural.

No entanto a relação de Vicente Dutra com a água mineral e do barro medicinal presentes na região datam de 1912 quando deu-se a descoberta das propriedades terapeuticas destes elementos, atraindo famílias que a partir de 1916 povoam o local. Destarte, constata-se a importância histórica da água mineral e da lama negra para o município quando se relaciona o surgimento do mesmo graças a tais atrativos naturais. Essa é a identidade cultural de uma população que vê o atual balneário como um monumento referencial e, até alguns anos atrás, como um motivo de orgulho. Com o passar dos anos, o empreendimento turístico vem sofrendo com a falta de incentivos financeiros que permitam a mantença da estrutura, sendo assim, muitos serviços antes disponibilizados, como sauna, banheiras de hidromassagem e atendimento clínico, perderam-se no tempo, ocasionando a desvalorização da edificação. 


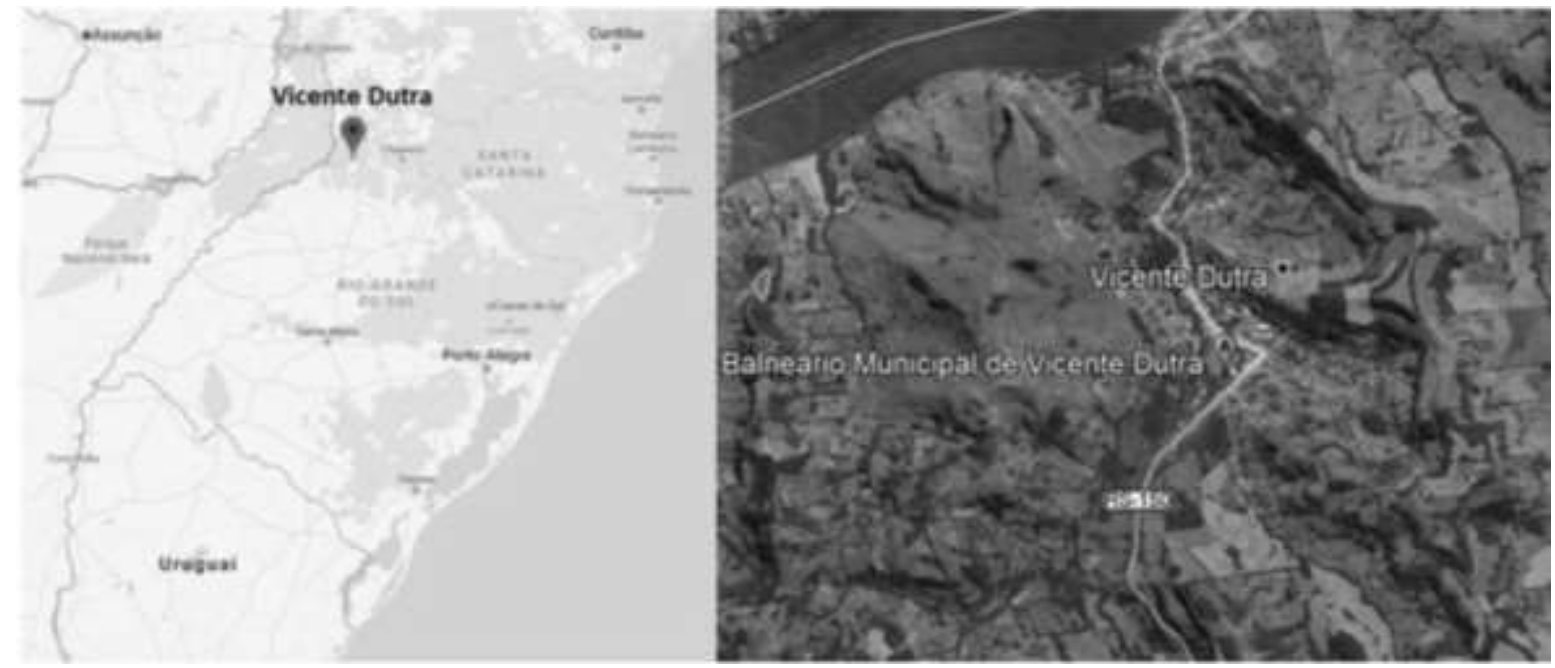

Figura 1: Localização geográfica de Vicente Dutra e do Balneário Municipal

Tratando-se de uma obra pública, é perceptível a desvalorização da mesma perante os olhos do poder municipal ou estadual, ao avaliar a situação física em que se encontra a edificação, a mais de uma década desamparada de incentivos financeiros para manutenções e reformas. Quando Choay (2006) fala do carácter genérico que deve compor as novas edificações ela está afirmando a importância do patrimônio como algo que deve ser preservado e não copiado, neste sentindo o Balneário de Vicente Dutra não representa um patrimônio pelo estilo arquitetônico antigo, pois o mesmo é relativamente recente, mas sim pela importância histórica e cultural que a palavra representa para a cidade e para a formação da identidade da comunidade local.

É de fundamental importância tratar da relação entre espaço e paisagem como fator determinante para a sociedade e, neste contexto, Santos (1997) afirma que cada vez que a sociedade passa por um processo de mudança, a economia, as relações sociais e políticas também mudam, num processo semelhante ao que ocorre na relação entre espaço e paisagem, que se transformam em busca de adaptação às novas necessidades da sociedade. Ainda, de acordo com este autor, essas alterações pelas quais a paisagem passa são apenas parciais, não mudam, tornando-se testemunhas do passado, por outro lado, muitas mudanças sociais não provocam modificações na paisagem.

Em Vicente Dutra, a vinculação entre o atual balneário e a sociedade atual já é uma demonstração de transição e transformação quando comparado com os antigos balneários e a evolução arquitetônica do empreendimento, entretanto, em um cenário mais atual também é possível analisar as transformações ocorridas desde o início da construção do que viria a ser uma moderna e ampla edificação em alvenaria, na década de 1960, com o apoio do então governador do estado Leonel Brizola , a conclusão da obra em 1975 com o apoio da extinta Companhia Rio-grandense de Turismo, passando pelas ampliações realizadas no ano de 2000, onde foram construídas as piscinas externas e em 2003 com a execução da piscina térmica, assumindo a configuração formal existente até os dias atuais, e assim compreender que o espaço se tornou testemunha e refém do tempo passado.

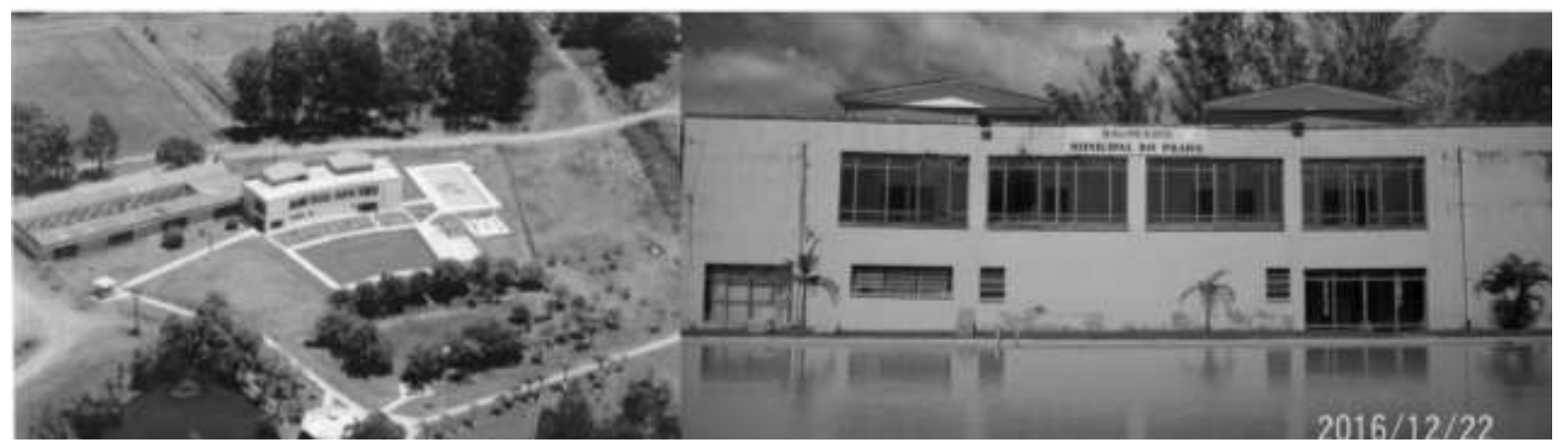

Figura 2: Balneário municipal, localização e vista externa da fachada principal

Concomitante a precariedade em que a edificação se encontra devido ao alto nível de degradação, fatores naturais também influenciam ou agravam os processos patológicos existentes na mesma. A água mineral, um dos grandes 
atrativos turísticos locais e existente em diversos poços no município, é utilizada para todos os serviços no balneário, desde limpeza até o abastecimento das piscinas, como a água mineral termal é, conforme dados obtidos com a prefeitura municipal, alcalina, radioativa, cloro sulfatada e bicarbonatada, assim processos químicos também podem estar incidindo sobre a construção, aliados aos processos de infiltração, condensação e umidade ascensional. Para melhor e maior compreensão sobre as características do balneário municipal foi desenvolvido um quadro resumido (Tabela 1) com a compilação das informações arquitetônicas e estruturais de maior relevância.

Tabela 1: Características arquitetônicas, estruturais e quanto ao revestimento da edificação

\begin{tabular}{|c|c|c|}
\hline \multicolumn{3}{|c|}{ Características da edificação } \\
\hline Arquitetônico e estrutural & Revestimentos & Alterações \\
\hline $\begin{array}{l}\text { Fundações tipo sapata, pilares e vigas } \\
\text { moldados e concretados in loco }\end{array}$ & $\begin{array}{l}\text { Piso com revestimento cerâmico, } \\
\text { áreas molhadas com revestimento } \\
\text { cerâmico nos pisos e paredes }\end{array}$ & \\
\hline $\begin{array}{c}\text { Alvenaria do andar térreo com } 30 \mathrm{~cm} \\
\text { de espessura em tijolo maciço }\end{array}$ & $\begin{array}{c}\text { Demais paredes internas com } \\
\text { revestimento de textura e pintura } \\
\text { acrílica }\end{array}$ & \\
\hline $\begin{array}{c}\text { Uso de platibanda e terraço jardim, } \\
\text { com sistema de tubulação das calhas } \\
\text { externo }\end{array}$ & Pintura externa acrílica & $\begin{array}{l}\text { O terraço jardim foi substituído por } \\
\text { telha fibrocimento }\end{array}$ \\
\hline $\begin{array}{l}\text { Lajes de concreto armado moldadas } \\
\text { in loco, marquises externas }\end{array}$ & $\begin{array}{l}\text { Impermeabilizações da } \\
\text { plabitanda com manta asfáltica }\end{array}$ & $\begin{array}{l}\text { Com o tempo as impermeabilizações } \\
\text { perderam a função }\end{array}$ \\
\hline Esquadrias em ferro e vidro comum & $\begin{array}{l}\text { No bloco do pavimento térreo, } \\
\text { onde encontram-se as banheiras } \\
\text { de hidromassagem, há cobogós } \\
\text { cerâmicos nos vãos das } \\
\text { esquadrias }\end{array}$ & \\
\hline Tubulações de ferro & $\begin{array}{l}\text { Inexistencia de pingadeiras nos } \\
\text { vãos das esquadrias e rufos nas } \\
\text { platibandas }\end{array}$ & $\begin{array}{c}\text { Tubulações de ferro dos banheiros do } \\
\text { térreo foram alteradas para P.V.C. }\end{array}$ \\
\hline
\end{tabular}

\section{ANÁLISE DAS PRINCIPAIS MANIFESTAÇÕES PATOLÓGICAS}

A análise das manifestações patológicas identificadas através de inspeção visual ocorre com enfoque na ação da umidade sobre a obra em estudo. Neste sentido, faz-se fundamental elucidar como os danos gerados pela umidade estão afetando a edificação e seus usuários, além de correlacionar com as possíveis intervenções a serem propostas com o intuito de recuperar este patrimônio material. Buscou-se adotar, portanto, a metodologia proposta por Lichtenstein (1985), como pode ser observada através da Figura 3. 


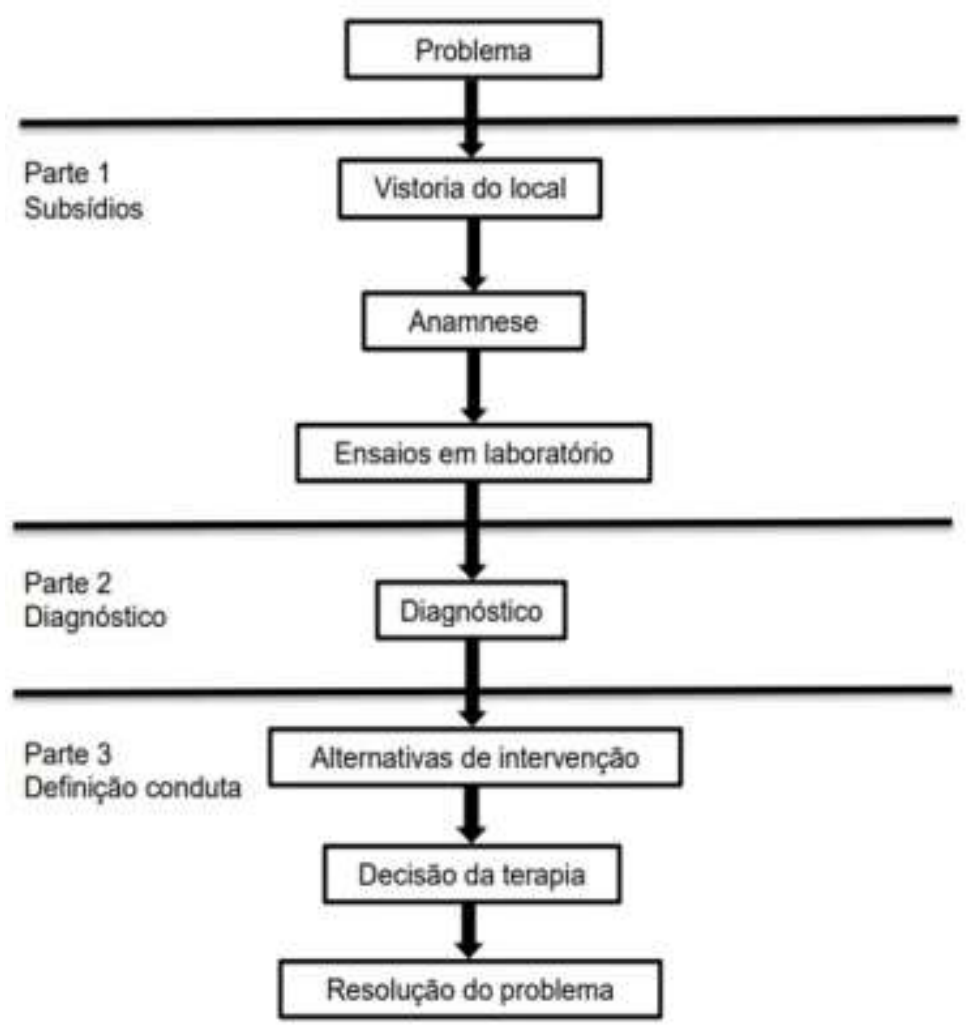

Figura 3 : Metodologia de análise das manifestações patológicas da edificação

A inexistência de manutenção preventiva aliada à contínua ação da umidade diminuem acentuadamente a vida útil da edificação. Processos patológicos decorrentes da incidência da água das chuvas, da umidade ascensional, por infiltração ou condensação são identificados com maior recorrência. As manifestações identificadas na edificação são apresentadas de acordo com a sua natureza e origem, bem como as possíveis intervenções, buscando o tratamento e a correção de tais anomalias.

\section{RESULTADOS}

\subsection{A edificação}

A edificação, como já fora supracitado, não traz consigo elementos icônicos da arquitetura antiga, entretanto seu projeto foi elaborado visando enaltecer a potencialidade turística local. Neste viés, a edificação é composta por três partes principais sendo exemplificadas na Figura 4. A área que engloba as banheiras de hidromassagem é determinada pelo setor 1 , a área da edificação composta por dois pavimentos como o setor 2 e, por fim a área da piscina térmica como o setor 3 . 


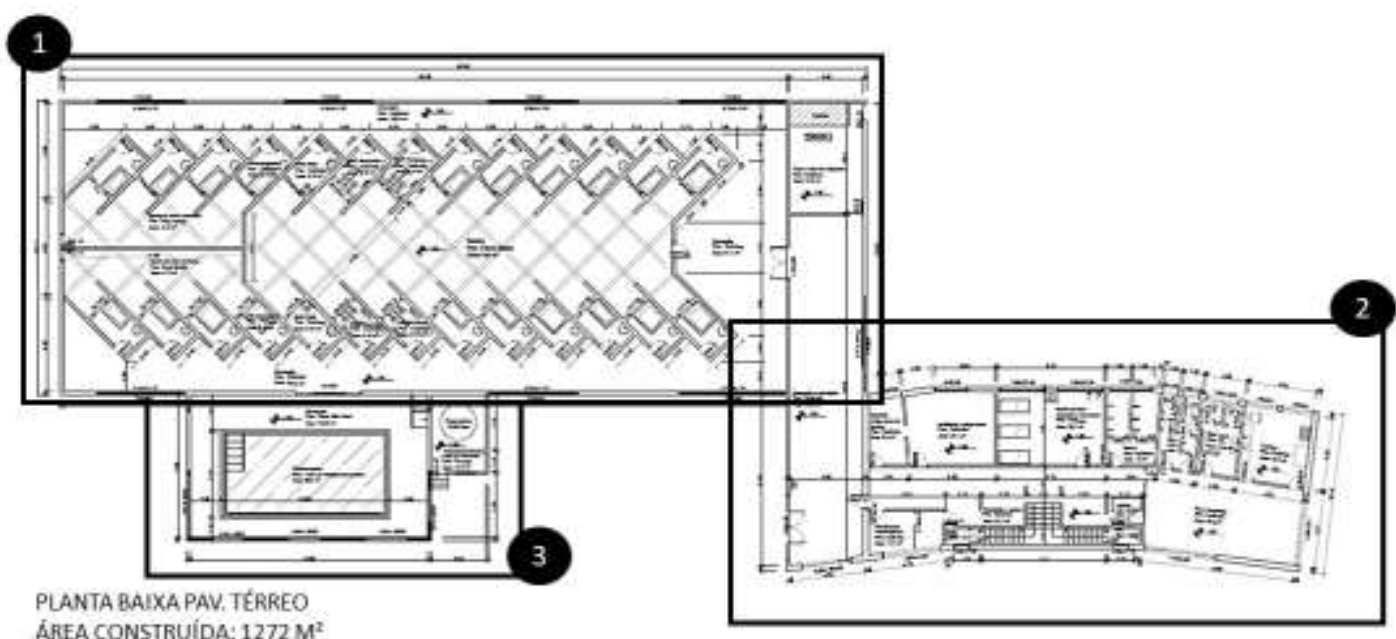

Figura 4: Planta baixa pavimento térreo da edificação com a determinação dos setores em estudo

O levantamento e identificação das principais manifestações patológicas presentes na edificação deu-se por meio de vistorias efetuadas no local, com auxilio de registros fotográficos que serão apresentados em sequência, elencando os ambientes onde tais imagens foram captadas, buscando exemplificar a situação de degradação e abandono pelo qual a obra passa e concomitantemente tratar dos possíveis diagnósticos e profilaxia.

\subsection{Mapeamento das manifestações patológicas no pavimento térreo}

$\mathrm{Na}$ figura 5 a seguir é apresentada a planta baixa do pavimento térreo com a marcação das condições patológicas existentes no local.

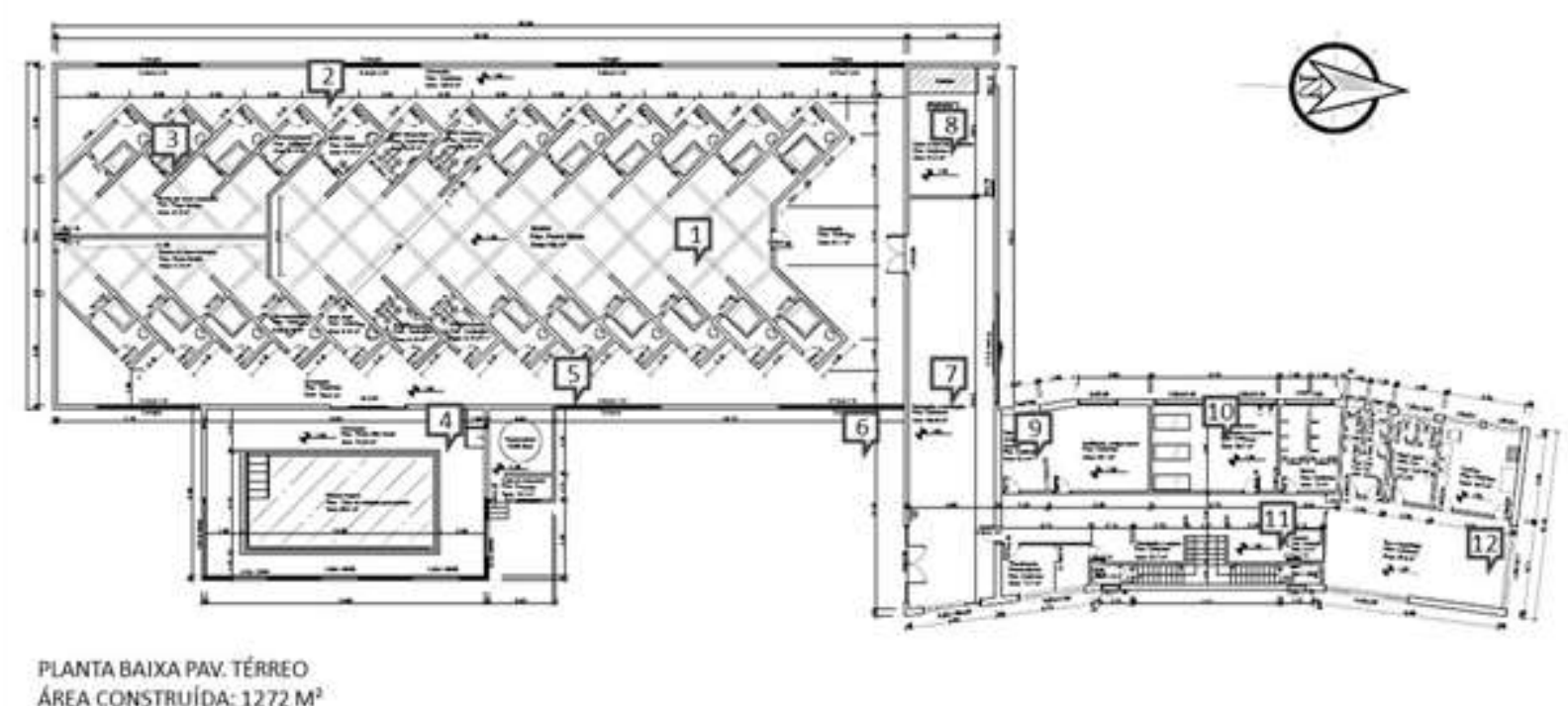

Figura 5: Planta baixa pavimento térreo da edificação com marcação das imagens das condições patológicas

Na parte da edificação que possui as banheiras de hidromassagem, Fig. 6.1, observou-se a ocorrência de sujidade na área externa da edificação destinada aos banhos de sol com a lama negra. Nas paredes externas também há a ocorrência de fissuras mapeadas, provavelmente desencadeadas por movimentações térmicas e retrações do reboco, além do crescimento de matéria orgânica, como plantas e fungos.

No teto dos corredores da edificação, Fig. 6.2, observa-se o desprendimento da pintura ocasionada devido a excesso de umidade, além de infiltração da água das chuvas através da laje de cobertura pelos dutos do sistema elétrico. 
Nas salas onde estão as banheiras de hidromassagem, Fig. 6.3, o que se observou, de um modo geral, é que as mesmas se encontram desativadas devido a problemas na caldeira que mantinha o sistema de aquecimento da água em funcionamento. A caldeira nunca foi arrumada (desde 2012 desativada) e as banheiras nunca voltaram a funcionar. Também é possível notar o surgimento de eflorescências, mofo e bolores nas paredes internas.

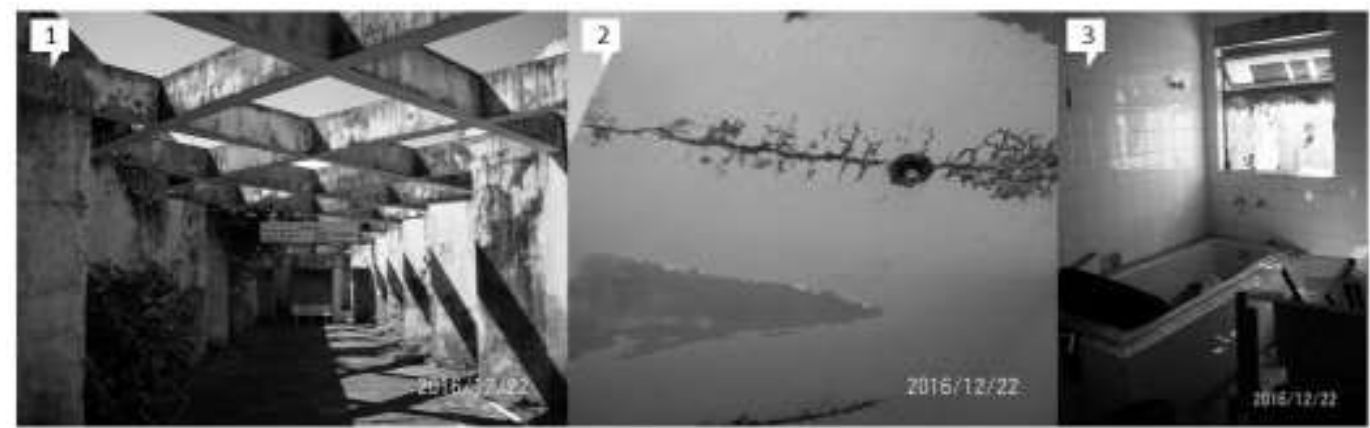

Figura 6: Manifestações patológicas encontradas na área de banho

$\mathrm{Na}$ parte da edificação onde fica situada a banheira térmica, Fig. 7.4, a mesma encontra-se desativada, havendo o acúmulo de sujeira. Nas paredes internas, há a ocorrência de destacamento da pintura, Fig. 7.5, provavelmente ocasionada pela presença de umidade provinda de infiltrações que ocorrem na cobertura da edificação e também da presença de umidade de condensação por se tratar de uma piscina térmica. Na parte externa da edificação, Fig. 7.6, a platibanda e a marquise que contornam o setor 1 apresentam sinais de acúmulo de matéria orgânica e destacamento da pintura. Há falta de manutenção preventiva e, assim como ocorre em calçadas que circundam a edificação, a água proveniente da chuva que cai na marquise, respinga para a platibanda onde ocorre o aparecimento de manchas de sujeira e acúmulo de umidade.

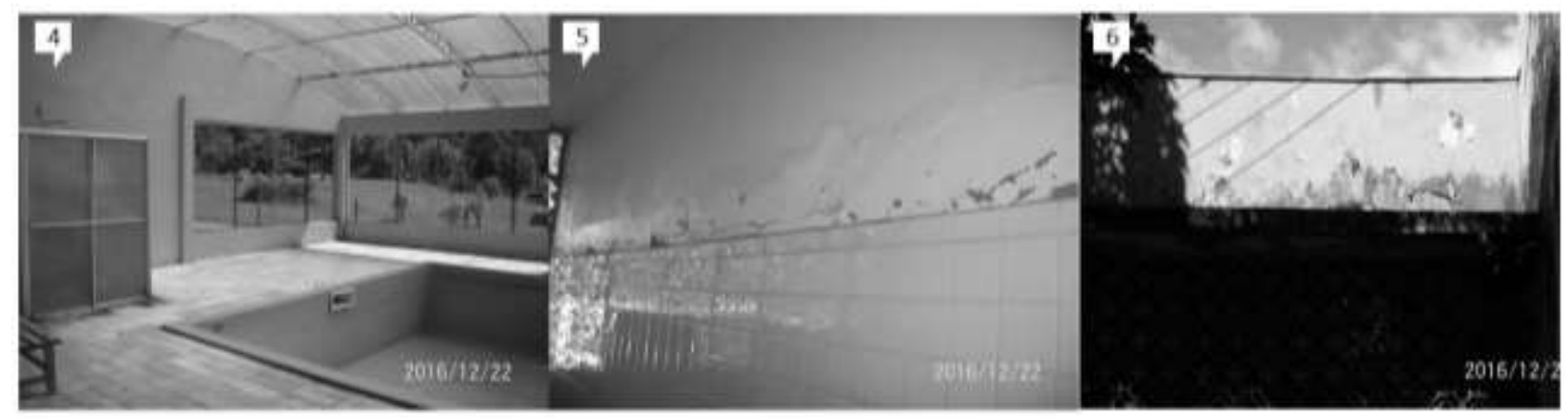

Figura 7: Manifestações patológicas encontradas na área de banho

No corredor entre a área das banheiras de hidromassagem (setor 1) e o pavimento térreo da edificação principal (setor 2), Fig. 8.7, houve o desplacamento da parte inferior da viga longitudinal do corredor. Como medida corretiva, observase que foi feita a aplicação de argamassa, porém questiona-se quanto o papel estrutural de tal material empregado na recuperação e a investigação da origem deste desplacamento. É de extrema importância que seja feito uma investigação do ponto de vista estrutural para averiguar se não houve o comprometimento da armadura, antes de aplicar qualquer técnica de correção.

Na sala da caldeira, Fig. 8.8, observa-se a sinais de infiltração e manchas de sujidade nas paredes. Na Fig. 8.9 é possível observar desplacamento do reboco ocasionado pela grande incidência de umidade, além do descolamento do revestimento textulizado devido a expansão dimensional causada pela criptoflorescência na sala onde até 2012 funcionou a sauna, mas que atualmente encontra-se abandonada. 


\section{CBPAT 2020

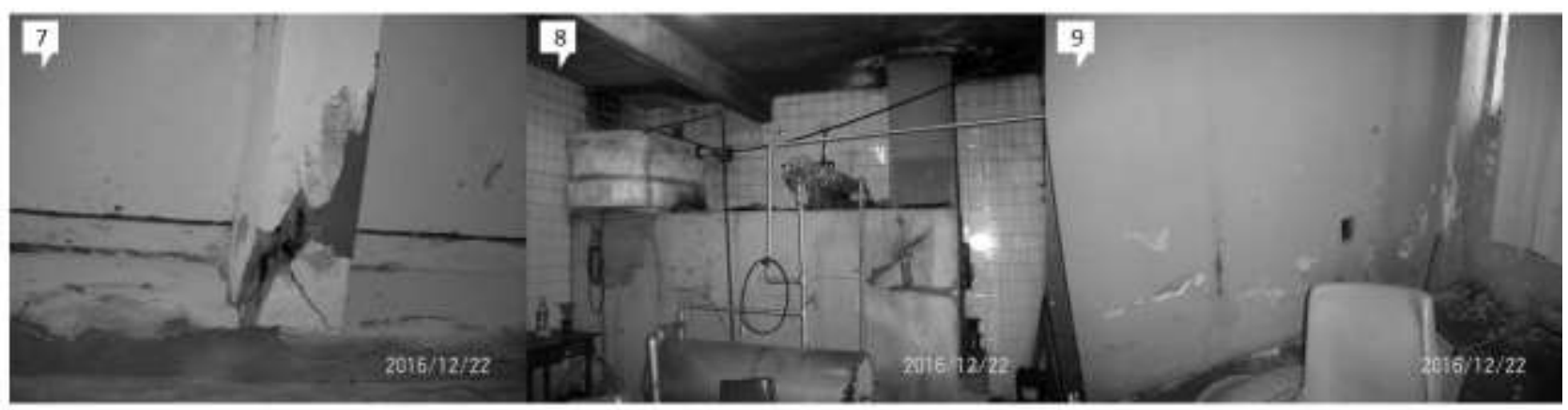

Figura 8: Manifestações patológicas encontradas na área de banhos

Outra sala do pavimento térreo da edificação principal (setor 2) que era utilizada como sala de massagens e atualmente serve como local de armazenamento de utensílios em desuso é apresentada na Fig. 9.10. A presença de eflorescências também é observada em elementos estruturais, como é o caso do pilar da Fig. 9.11, observando-se também a desagregação da argamassa de regularização.

Na Fig. 9.12 à descaracterização das aberturas da edificação. As aberturas são todas metálicas e devido a ação conjunta do tempo associado as condições ambientais locais e a falta de manutenção fizeram com que a pintura fosse se descolando com o tempo e o metal sofresse oxidação e perca dimensional.

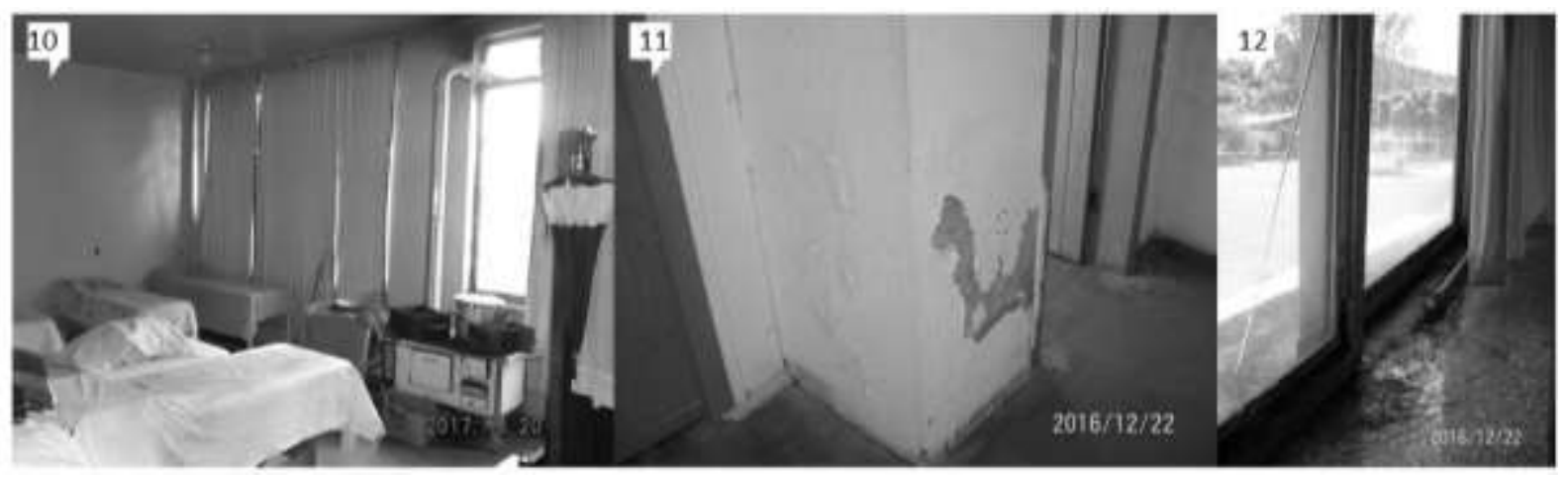

Figura 9: Manifestações patológicas encontradas encontradas no pavimento térreo do setor 2

\subsection{Mapeamento das manifestações patológicas no pavimento superior}

Considerando as manifestações patológicas identificadas até o presente momento, salienta-se que as mesmas, apesar de causarem grande desconforto aos usuários, são cabíveis de recuperação, em sua maioria. Na sequência, são apresentadas as principais manifestações patológicas identificadas no pavimento superior da edificação principal, onde observou-se que o grau de deterioração é expressivo.

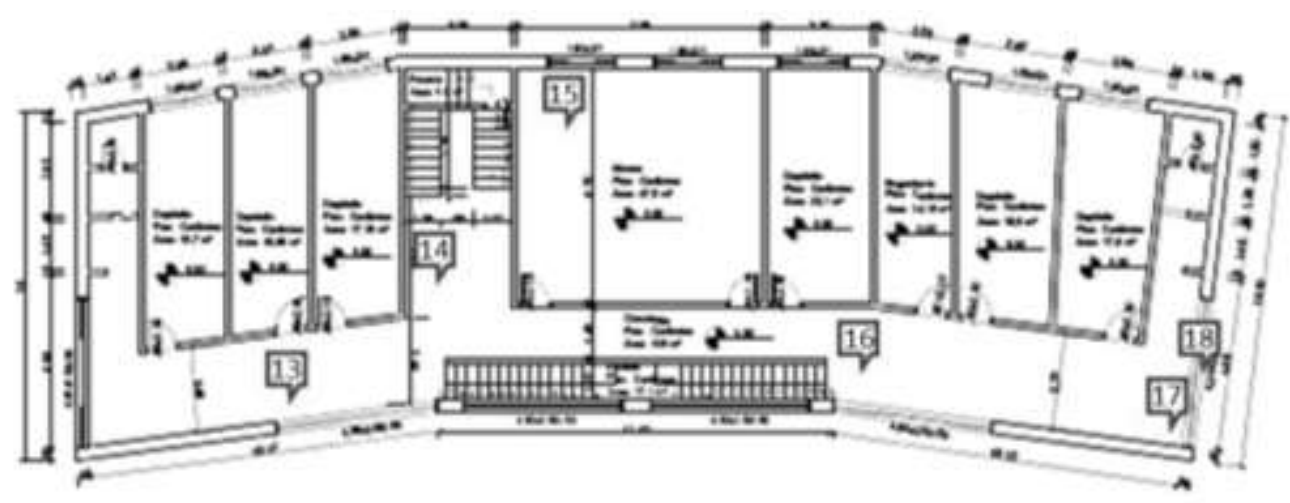

PLANTA BAIXA PAV SUPERIOR

AREA CONSTRUIDA:294 $\mathrm{M}^{2}$

Figura 10: Planta baixa pavimento superior da edificação com marcação das imagens das condições patológicas 


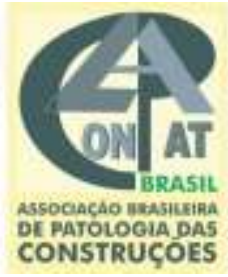

De um modo geral, as manifestações patológicas identificadas no pavimento superior da edificação principal, possuem a provável causa decorrente de falhas na impermeabilização da laje de cobertura, ineficácia da cobertura e provável insuficiência da calha. Por meio da Fig. 11 pode-se identificar que a manta asfáltica que circunda a platibanda encontrase em péssimo estado de conservação, havendo o descolamento da mesma, também foram identificadas falta de manutenção e limpeza da calha, obstruindo a passagem da água.

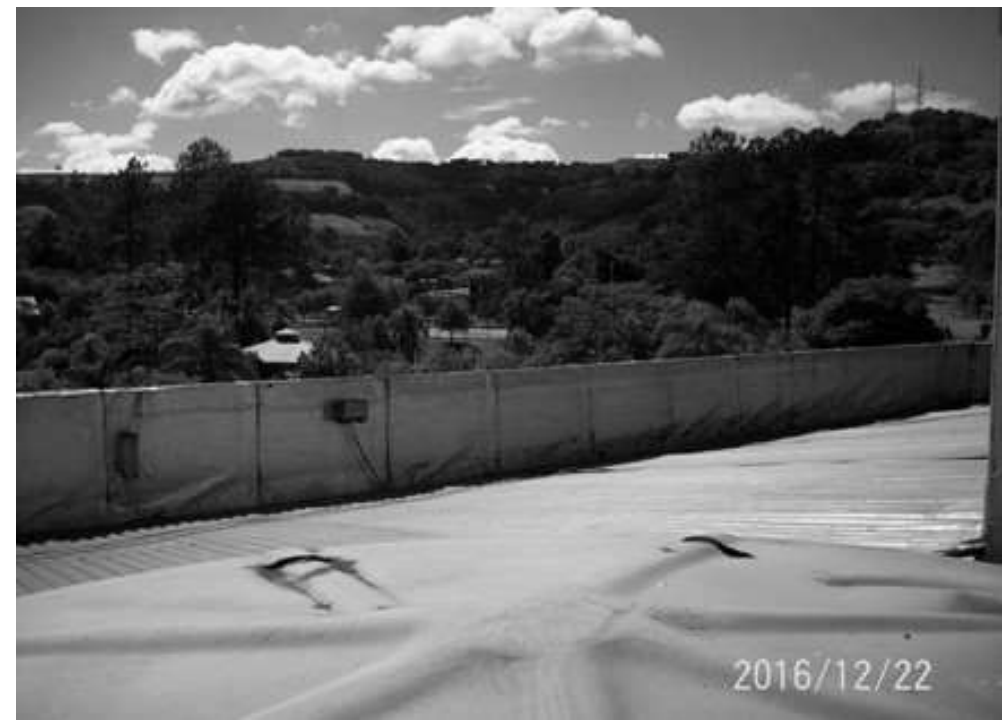

Figura 11: Vista da cobertura da edificação

Como fora supracitado, a grande maioria das manifestações patológicas identificadas no pavimento superior da edificação tem como provável causa a água que infiltra devido aos problemas existentes na cobertura da edificação. $\mathrm{Na}$ Fig. 12. 13 observa-se a ocorrência de fissuras, desplacamento e desagregação do concreto decorrentes da corrosão da armadura.

Na Fig. 12.14 há a ocorrência de criptoflorescências e na Fig. 12.15 há o aparecimento de mofo e fungos na superfície das paredes.

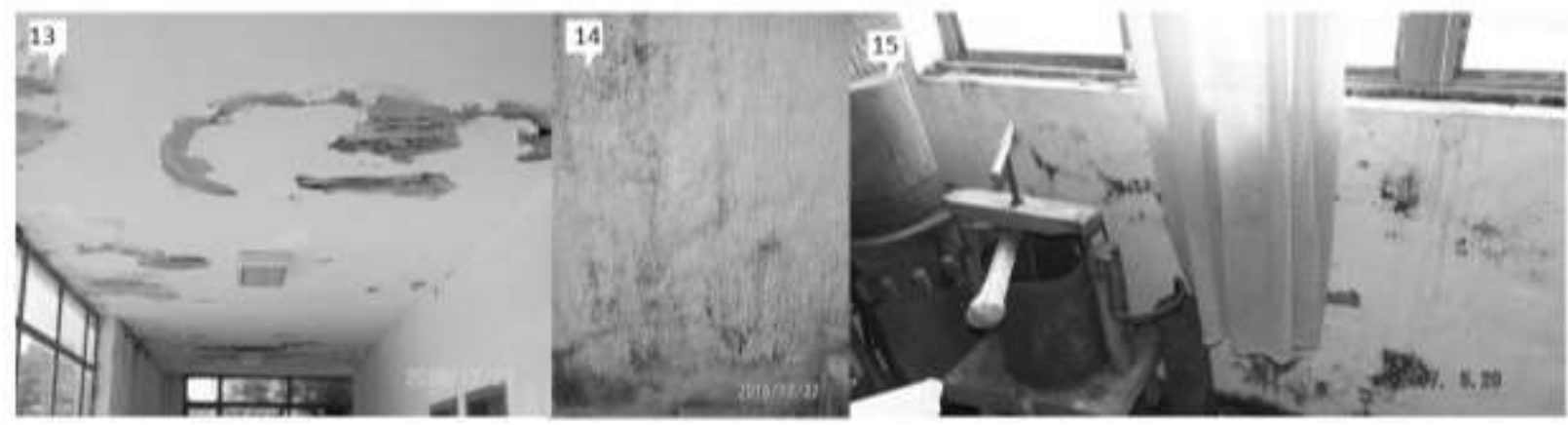

Figura 12: Manifestações patológicas no pavimento superior da edificação

A ocorrência de corrosão da armadura da laje de cobertura, desagregação do concreto, fissuras mapeadas, fungos e eflorescências também são identificados na Fig. 13. A correlação de tais manifestações patológicas com a ação da chuva e aos problemas com a impermeabilização da laje da cobertura é confirmada pelos relatos de funcionários que trabalham no local, onde são identificados vários locais onde a água penetra em dias de chuva. 


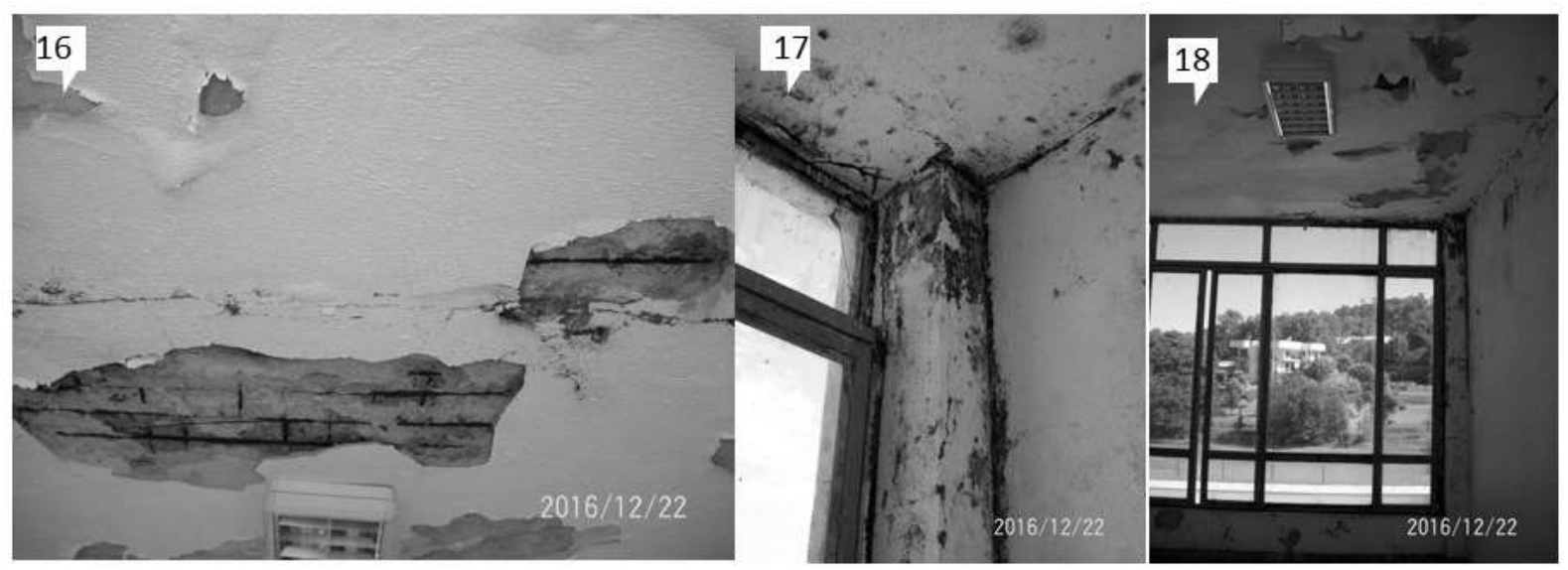

Figura 13: Manifestações patológicas no pavimento superior da edificação

\subsection{Terapêutica e profilaxia das manifestações patológicas}

Por meio da vistoria efetuada no local, são apresentadas a seguir as prováveis sugestões de correção para as manifestações patológicas encontradas na edificação.

- Descaracterização das esquadrias: A maioria das esquadrias necessitam ser substituídas por novas esquadrias e as demais devem passar por limpeza, lixamento e pintura com tinta específica.

- Infiltração: Devido ao estado de conservação comprometido da manta asfáltica, sugere-se refazer a estrutura do coberto, promovendo a construção de uma calha adequada e de fácil manutenção além de uma nova impermeabilização nas platibandas e na laje superior.

- Inchamento do reboco: Primeiramente recomenda-se a retirada do reboco degradado nas partes mais afetadas e refazendo-o posteriormente quando necessário e repintura com tinta emborrachada.

- Incrustação: Limpeza adequada das regiões da edificação afetadas e novo reboco caso a situação de biodegradação esteja avançada ou apenas a recuperação da cor antiga.

- Danos estruturais: A ação da infiltração na laje superior provocou corrosão das armaduras da laje, desencadeando a queda do reboco e expondo as armaduras da laje. Recomenda-se que seja feita uma avaliação dos danos estruturais causados pela corrosão das armaduras, com um projeto de reforma e escoramento estrutural realizado através de uma equipe especializada.

- Descascamento da pintura: Remoção da camada de tinta danificada, limpeza adequada e repintura com tinta específica.

\section{CONCLUSÕES}

As manifestações patológicas identificadas na sede do balneário municipal de Vicente Dutra são, em sua grande maioria, e como pôde-se observar por meio da vistoria efetuada no local, decorrentes da excessiva presença de umidade existente na edificação. Foi identificada umas das causas principais como sendo os defeitos encontrados na cobertura da edificação, desencadeando os processos secundários observados na parte interna da edificação.

Entretanto, considera-se também como agravante, a falta de manutenções preventivas no local, o fator de localização, pois a cidade de Vicente Dutra faz divisa fluvial com a cidade Mondaí em Santa Catarina, portanto a proximidade com o Rio Uruguai faz com que a umidade do ar seja sempre elevada no município. Além disso, pela cidade ser fonte de água mineral, não se descarta a hipótese de que esta água tenha sido utilizada para a confecção do concreto e argamassa utilizados na edificação.

De um modo geral, o objetivo do estudo foi contemplado, pois foram identificadas as principais manifestações patológicas presentes na edificação em estudo. Entretanto, recomenda-se que seja aprofundado tal estudo, avaliando detalhadamente os possíveis danos estruturais sofridos, considerando a importância cultural da edificação para o município, propondo sua reabilitação e devolvendo à população um importante símbolo da riqueza hidromineral da cidade. 


\section{REFERÊNCIAS}

BRASIL. INSTITUTO BRASILEIRO DE GEOGRAFIA E ESTATÍSTICA. Rio Grande do Sul - Vicente Dutra: Censo Demográfico 2010: Resultados da Amostra - Características da População. 2010. Disponível em: http://cidades.ibge.gov.br/xtras/temas.php?lang=\&codmun=432310\&idtema=90\&search=rio-grande-do-sul|vicentedutra|censo-demografico-2010:-resultados-da-amostra-caracteristicas-da-populacao-. Acesso em: 15 mar. 2017

CAPORRINO, Cristiana Furlan. Patologias em alvenarias. 2 ed ed. São Paulo.

CHOAY, Françoise. A alegoria do patrimônio. 4. ed. São Paulo: Unesp, 2006. Tradução de Luciano Viera Machado, p. 254.

ESTADO DO RIO GRANDE DO SUL. MINISTÉRIO DO TURISMO. Rota das Águas e Pedras. Disponível em:http://www.turismo.rs.gov.br/roteiro/55/rota-das- aguas-e-pedras-preciosas. Acesso em: 10 abr. 2017.

LICHTENSTEIN, N. B. Patologia das construções: procedimento para formula para formulação do diagnóstico de falhas e definição de conduta adequada à recuperação de edificações. São Paulo, 1985. 191p. Dissertação (Mestrado). Escola Politécnica da Universidade de São Paulo.

LOPES, Caryl Eduardo Jovanovich. Técnicas retrospectivas. Santa Maria, [s.d.].

MESQUITA, Esequiel; VARUM, H. Boletín Técnico. [s. 1.], n. January, 2016.

MOTTA, Lia; REZENDE, Maria Beatriz. Inventário. In: GRIECO, Bettina; TEIXEIRA, Luciano; THOMPSON, Analucia (Orgs.). Dicionário IPHAN de Patrimônio Cultural. 2. ed. rev. e ampl. Rio de Janeiro, Brasília: IPHAN/DAF/Copedoc, 2016. ISBN 978-85-7334-299-4.

Prefeitura Municipal de Vicente Dutra. Nosso Município. 2017. Disponível em: http://www.vicentedutra.rs.gov.br/nossomunicipio. Acesso em: 20 nov. 2017.

Prefeitura Municipal de Vicente Dutra. Turismo. 2017. Disponível em: http://www.vicentedutra.rs.gov.br/nossomunicipio. Acesso em: 20 nov. 2017.

SANTOS, F. Análise estrutural de uma edificação histórica do século XVIII. Anais do Congresso Brasileiro de Patologia das Construções - CBPAT, [s. 1.], n. April, p. 1-11, 2016.

SANTOS, Milton. Pensando o espaço do homem. 4. ed. São Paulo: Editora Hucitec, 1997, p. 21- 54. VERÇOZA, Ênio José. PATOLOGIA DAS EDIFICAÇÕES (1).pdf. Porto Alegre, 1991. 